\title{
THE SPECTRAL DISTRIBUTION OF ENERGY REQUIRED TO EVOKE THE GRAY SENSATION ${ }^{1}$
}

\author{
By Irwin G. Priest ${ }^{2}$
}

\section{ABSTRACT}

The chief significance of this paper lies in the development and testing of an experimental method for determining an objective physical standard of "white light." The standard to be determined is the Planckian ("black-body") distribution of energy required to evoke the hueless sensation of brilliance, commonly called "white" or "gray," under certain standard conditions stated in detail in the paper.

The method of producing and adjusting the spectral distribution of the stimulus is this: Light from a lamp of known spectral distribution is modified by rotatory dispersion in a system of quartz plates and nicol prisms in such a way that by rotating one of the nicols the light emerging from it can be made to assume the spectral distribution of a Planckian radiator at any desired temperature between 4000 and $7000^{\circ} \mathrm{K}$. Such a system is, in effect, a selective light filter of adjustable spectral transmission.

Two methods of observation are described:

(I) The method of adjustment by trial, in which the observer himself adjusts the stimulus until he calls the sensation "white."

(2) The method of answers, in which the operator conducting the experiment adjusts the stimulus to correspond to certain fixed temperatures of the hypothetical Planckian radiator and records the observer's reactions as "blue," "white," or "yellow," as the case may be. The latter method proved to be the more satisfactory.

Experimental results are given from four observers. The average results of these observers indicate that "white light" may be represented: ( 1 ) Theoretically, by the light from a Planckian radiator at a temperature of about $5200^{\circ}$ absolute; (2) practically, to a fair approximation, by average noon sunlight at Washington. It is, however, emphasized that the final establishment of such a standard should be based on a more extensive statistical investigation.

An appendix to the paper sets forth the desirapility of an extensive statistical determination and correlation of the characteristics of vision.

1 The substance of this paper was first presented at a joint meeting of the American Physical Society and the Optical Society of America in Chicago, Dec. 29, 1920.

'The author acinowledges the cooperation of Prof. C. A. Skinner, Dr. M. Katherine Frehafer, and Mr. H. J. McNicholas as observers in this investigation, and their advice as well as that of Dr. P. V. Wells in rerising the manuscript of this paper. Special credit is due to Mr. J. Clacey, optician, Bureau of Standards, for the construction of a standard quartz plate. 
I. Introduction

I. General considerations. . . . . . . . . . . ${ }^{2} 3^{2}$

2. Purpose and scope of this investigation . . . . . . . . . . . ${ }_{23} 6$

II. Experimental methods................................. 238

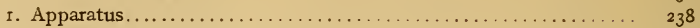

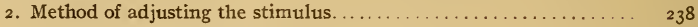

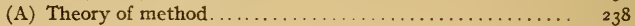

(B) Experimental verification of method............. $24 \mathrm{r}$

3. Methods of observation ............................ 246

(A) Method of adjustment by trial . . . . . . . . . . . 246

(B) Method of answers ............................... 246

III. Experimental results............................... 247

1. Effect of previous selective fatigue.................. 247

2. Results by the method of adjustment by trial ............ 248

3. Results by the method of answers.................... 249

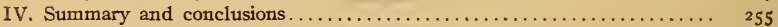

I. Principal conclusions............................ ${ }_{255} 55$

2. Incidental conclusions............................ ${ }_{25} 6$

3. Suggestions as to future work ...................... 259

Appendix: The desirability of an extensive statistical determination and correlation of the characteristics of vision $\ldots \ldots \ldots \ldots \ldots \ldots \ldots, \ldots \ldots \ldots, 260$

Bibliography $\ldots \ldots \ldots \ldots \ldots \ldots \ldots \ldots \ldots \ldots \ldots \ldots \ldots \ldots, 264$

\section{INTRODUCTION}

\section{GENERAL CONSIDERATIONS}

The Planckian spectral distribution of energy serving to specify the normal stimulus for the hueless visual sensation commonly known as "white" or "gray" should naturally take rank among the most significant cardinal data of the pure science of physiologic optics. Moreover, a quantitative knowledge of the normal stimulus of gray is obviously of fundamental importance to the practical technologic problems of rational color specification; it must be, in fact, the basis of the solution of the problem of defining "white" light. Nevertheless, it does not appear that any serious attempt has been made heretofore to determine this stimulus experimentally.

The concept of a "black-body" energy distribution as a definition for the stimulus of "white" was definitely proposed by H. E. Ives in rgro. He also showed that the energy distribution of "average daylight" could be represented by a "black body" at about $5000^{\circ} \mathrm{K}$, and inferred, without any rigorous demonstration or attempt at experimental proof, that this definition of "average daylight" might be considered interchangeable with the definition of "white light." 3 
The desirability of making such an experimental determination was pointed out several years ago by Troland. He stated the case very clearly, as follows: ${ }^{4}$

There has been considerable discussion, in connection with colorimetric procedure, concerning the definition of "white light." It seems to me obvious that "white light" or "white" radiation can be defined logically only with reference to the properties or reactions of the normal human visual apparatus. White radiation is radiation which produces the sensation of white, or the achromatic visual quality, whether it be white or some shade of gray. The existence of complementary pairs of colors makes it evident that there must be an infinite number of difierent combinations of wave lengths which will produce this sensation, and consequently it becomes desirable to add the further criterion that "white" radiation must have the distribution characteristic of a black body. The tendency to identify white light in this sense with solar radiation, or with black body radiation corresponding as nearly as possible with solar radiation, is based upon the hypothesis that sunlight actually produces the sensation of white. If Hering's assertion, already referred to, is correct, this hypothesis can not be retained. [Hering claims daylight is yellowish.]

About this same time the present author was making a few preliminary determinations. ${ }^{5}$ Subsequent experience has shown that the tentative results of these first experiments have no quantitative value. They are without significance because of the following circumstances:

(r) The stimuli did not actually conform sufficiently closely to the Planckian formula.

(2) The field viewed was not large enough to permit of good color discrimination.

(3) Sufficient care was not taken as to standard conditions of observation, particularly in avoiding the effect of previous fatigue. ${ }^{6}$

(4) The method of observation (adjustment by trial) was not good. ${ }^{7}$

The elementary concepts upon which the present investigation is based are these:

(I) The energy radiated by a so-called complete or ideal radiator ("black body") may be expressed as a function of temperature and wave length by the Planckian ${ }^{8}$ formula:

where $\lambda \equiv$ wave length;

$$
E=\frac{c_{1}}{\lambda^{5}\left(e^{\frac{C_{2}}{\lambda T}}-1\right)}
$$

$T \equiv$ absolute temperature of source;

$e \equiv$ base of natural logarithms;

$c_{1}$ and $c_{2}$ are constants;

$E \equiv$ energy per unit wave length.

4 Troland, Trans. I. E. S., 13, p. 26; 1918.

B Priest, Trans. I. E. S., 13, pp. 75-77; 1918.

- Compare Sec. III, 1, below.

7 Compare Sec. III, 2, below.

Max Planck, Verh. d. Deutsch. Phys. Ges., 2, pp. 202-204; 1900. 
In the present instance we are interested only in relative energies which are given by any arbitrary value of $c_{1}$. Throughout this paper we accept ${ }^{4} 45^{\circ}$ micron-degrees as the value ${ }^{3}$ of $c_{2}$. We express wave length in millimicrons $\left(m \mu \equiv\right.$ meter $\left.\times 10^{-0}\right)$, and temperature in degrees $\mathrm{K}$ (absolute temperature $=$ centigrade +273 ).

(2) All common incandescent solid light sources (oil and gas flames, electric incandescent lamps, both carbon and metal filaments) as well as the sun conform approximately to the Planckian formula.

(3) The energy radiated by an incandescent source at comparatively low temperatures (say, $1000^{\circ} \mathrm{K}$ ) evokes the sensation known as red, which changes through orange and yellow as the temperature rises until, for very high temperatures, the sensation approximates "gray" or "white," the hueless sensation of brilliance.

(4) The theoretical spectral distributions of light from a complete radiator at various temperatures may be represented as shown in Fig. I. ${ }^{10}$ The wave length of the centers of gravity ${ }^{11}\left(\lambda_{c}\right)$ of the curves in Fig. $I$ is shown as a function of temperature in Fig. 3.

(5) We would infer from Figs. 1 and 3 , in connection with the facts noted under paragraph 3 just above, that the sensation evoked by the light from a source at a sufficiently high temperature would be white, and that at temperatures still higher the sensation would be blue. That is, with regard to the hypothetical Planckian radiator, we can conceive of a transition temperature below which its light evokes the yellow sensation, above which it evokes the blue sensation, and at which it evokes the white sensation.

(6) The highest temperature at which it is possible to operate an artificial incandescent light source conforming even approximately to the Planckian equation ${ }^{12}$ is less than $4000^{\circ} \mathrm{K}$, which is below the transition temperature mentioned. It is therefore impossible to verify by direct experiment our presumption in regard to the existence of this transition temperature.

'Coblentz, B. S. Sci. Paper No, 284. D. 470; 1916. Forsythe, Report on pyrometry. J. Op. Soc. Am., 4. p. 332: 1920 .

${ }_{10}$ The ordinates of these so-called "luminosity curves" represent the product: energy $X$ visibility, and are based on a tentative standard for average visibility. This tentative standard is shown by the dotted line in Fig. 2. It is the same as used in two previous papers (J. Op. Soc. Am., 4. p. 398, and J. Op. Soc. 4. p. $47 x$, Fig. 8, solid curve), and is adhered to throughout the present paper. It is nearly the same as the standard adopted by the Illuminating Engineering Society shown by the solid line in Fig. 2.

${ }^{11} \mathrm{Cl}$. Priest, Color and spectral distr:bution, J. Op. Soc. Am., 4, p. 389; 1920.

${ }^{12}$ Crater of the carbon arc. 


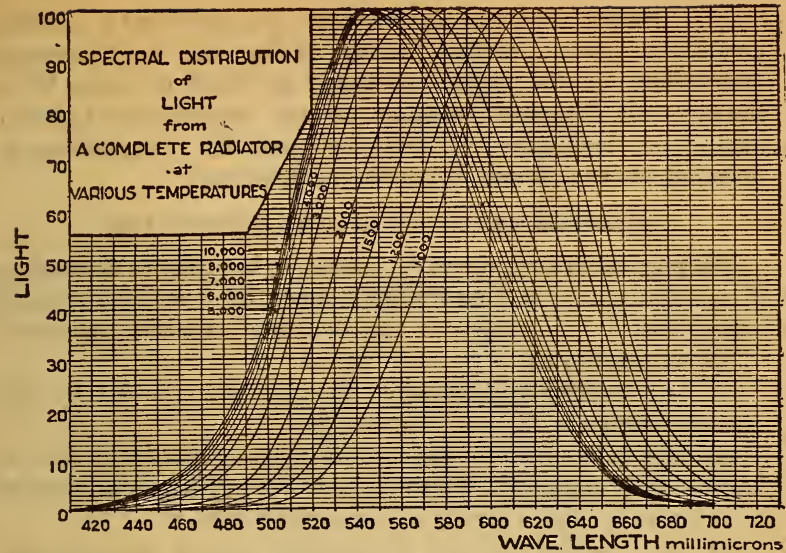

Frc. I,-Spectral distribution of light from a Planckian radiator at various temperatures Numbers attached to the curves indicate temperatures in degrees $\mathbf{K}$.

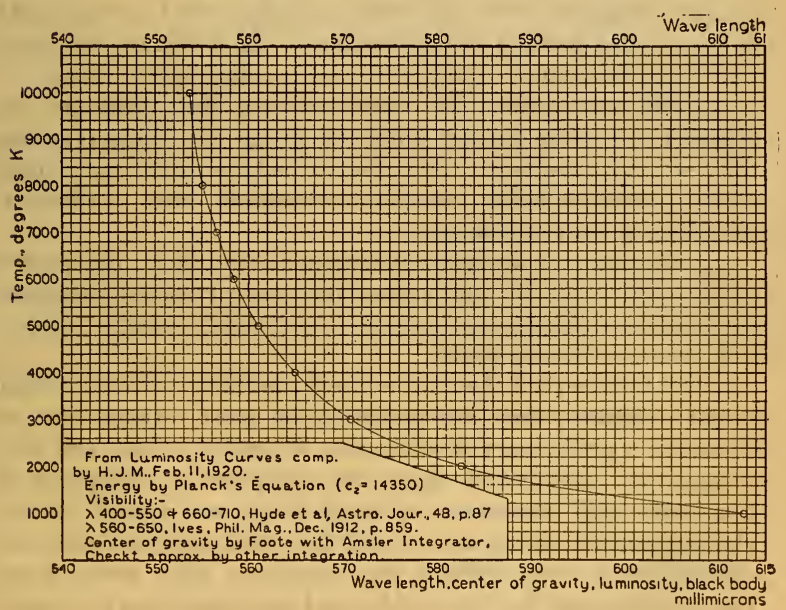

FiG. 3.-Relation between temperature and the wave length of the center of gravity of the spectral distribution of light for the Planckian radiator

Plotted from determinations of the centers of gravity of the curves shown in Fig. $x$. 
(7) However, as will be shown below, it is possible by suitable artifices to obtain radiant energy having the same spectral distribution (in the visible spectrum) as would be given by a hypothetical Planckian radiator at any temperature between about 4000 and $7000^{\circ} \mathrm{K}$, and the transition temperature in question has been found to fall within this range.

\section{PURPOSE AND SCOPE OF THIS INVESTIGATION}

The purpose of the present investigation has been to determine, in a preliminary way, for a few individuals, the Planckian spectral energy distribution which evokes the gray sensation under the following conditions:

(I) The uniformly illuminated circular field viewed by the observer subtends about $3.5^{\circ}$ at his eye.

(2) This field is surrounded by a completely dark field (except for the small amount of diffuse light in the apparatus in some of the observations). There is no comparison field.

(3) The absolute intensity is chosen to give a medium comfortable brilliance, such as to give no conspicuous afterimages in the dark; and it was determined that considerable positive and negative departures from this intensity had no effect on the results. In the second method of observation ${ }^{13}$ the brilliance was maintained approximately constant for all spectral distributions.

(4) The observations are conducted in a dark room and the observer's eyes are further protected by an eye shade following the contour of the face. The observer is kept in the dark about ro to 15 minutes before observations begin in order to eliminate the effect of previous fatigue. ${ }^{14}$

(5) The observer selects by one method or another ${ }^{15}$ the spectral distribution which for him evokes the gray or hueless sensation. $\mathrm{He}$ is asked to distinguish between "cold bluish white," "white," and "warm yellowish white."

It will be observed that, while these conditions are to a certain extent arbitrary, they are probably the most rational ones to impose in a preliminary investigation of limited extent, and they at any rate approximate closely the conditions of observation in colorimetry with instruments of usual design and methods of use. The size of field should be at least that used here, for color discrimination is very difficult and uncertain with small fields. That a comparison field can not be used is obvious from the nature

${ }^{13}$ See Sec. II, 3, B, below.

it See Sec. III, x, below.

${ }^{25}$ See Sec. II, 3, A and B, below for two methods used. 
Scientific Papers of the Bureau of Standards, Vol. 17

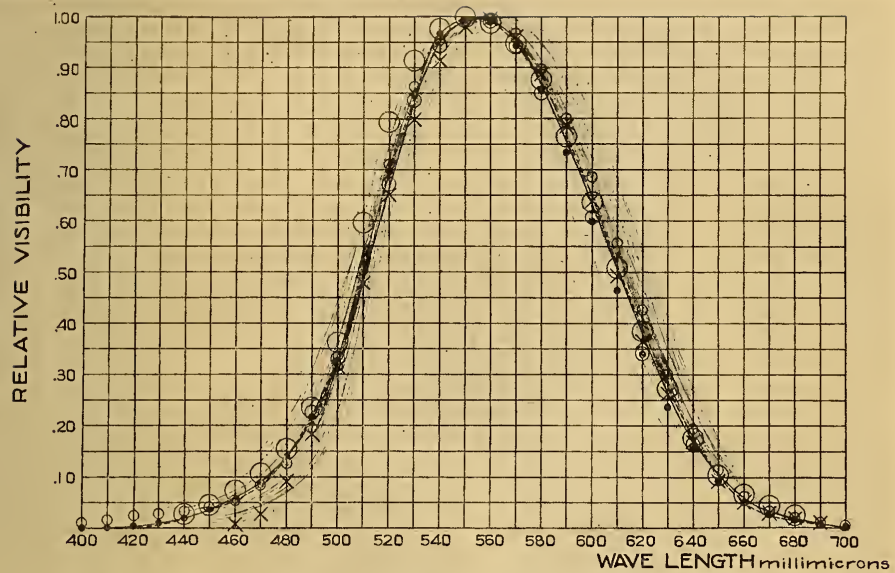

Gray background of curves: 125 individuals by Coblentz \& Emerson: D.S.Sci.Pap.303,Fig.19;19i7. - Hyde, Forsythe \& Cady: Astrop J.48 p. 67, TableIV;19i8.(Average of 10-29 individuals)

0 Coblentz \& Emerson: B.S SciPap.303, Table 5:1917. (Average of ias individuals)

Q P Nutting Trans I.E.S. 9, p.637, last line; 1914. (Average of 21 individuals)

(1) Ives: Phil. Mag.(6)24p.859jIableil ; 1912. (Average of 18 individuals)

IES. committee mean. (From Nutting:Jour. Op. Soc. Am 4 p.58; 1920)

Tentatively adopted by Priest; "Leucoscope;, Fig.0, Jour. Op.Soc'Am. Nov. 1920 (nearly coincident with I.E.S.)

$\times \times \times$ Recommended by Ives as standard for physical photometry:JFranh. Ins. 108.P. 220, Table I; 1919.

FIG. 2.-Synopsis of visibility data 
of the question to be answered. 'That fatigue must be guarded against is a reasonable precaution, the necessity of which will also be shown in the experimental part of this paper. ${ }^{16}$

Under these conditions we have determined the Planckian energy distribution which evokes the gray sensation for four different observers and have expressed the findings in terms of the absolute temperature of the Planckian hypothetical complete radiator. Sufficient observations have been made to determine these temperatures with considerable accuracy for these particular observers.

It has been shown that the transition from yellow to blue under these conditions is a real and obvious phenomenon, and that positive, unambiguous results may be obtained in determining the temperature of the source corresponding to this transition.

The purposes of this paper are:

(I) To describe the experimental method followed and show its utility for such investigations;

(2) To present the limited data already found for four individuals.

In regard to these observers, the following information may be given:

Visibility.-The visibility of radiant energy has been determined for two of the observers (H. J. M. and I. G. P.) by Coblentz and Emerson and is on record. ${ }^{17}$ H. J. M. was classed by Coblentz and Emerson as "normal;" I. G. P., as "subnormal red." The latter's departure from normal is comparatively small. ${ }^{18}$

Color perception.-The color perception of all the observers is approximately normal as judged by Holmgren's test and their ability to arrange colored samples in spectral order. As judged by Nagel's cards there is reason to suspect that two of the observers should be classed as "anomalous trichromats" (C. A. S. and H. J. M.), but this evidence is not conclusive. They exhibit a slight tendency to confuse green and gray in this test. All can read Stilling's charts.

16 Compare Sec, III, $x$.

17 B. S. Sci: Papers, No. 303, pp. $184-185 ; 1917$.

${ }_{10} \mathrm{Cf}$. J. Op. Soc. Am., 4, p. 47x, Fig. 8; 1920. $51645^{\circ}-21 \longrightarrow 2$ 


\section{EXPERIMENTAL METHODS}

\section{APPARATUS}

The essential parts of the apparatus used in this investigation to control spectral distribution are shown in Fig. 4. The actual apparatus used was part of the Arons chromoscope ${ }^{10}$ with an auxiliary quartz plate and nicol, as shown in Fig. 5, the auxiliary parts being placed between nicol $\mathrm{P}^{\prime \prime}$ and the source. The auxiliary nicol and the nicol $\mathrm{P}^{\prime \prime}$, with the auxiliary $0.500 \mathrm{~mm}$ plate between them, play, respectively, the parts of nicols I and 2 in Fig. 4. Likewise, nicols $\mathrm{P}$ and $\mathrm{A}$ with a $0.500 \mathrm{~mm}$ quartz plate between them play the parts of nicols 2 and 3 . The angle $\phi_{1}$ (nicol $\mathrm{P}^{\prime \prime}$ and auxiliary nicol $)^{20}$ is set permanently at $170^{\circ}$. The angle $\phi_{2}$ (nicols $\mathrm{P}$ and $\mathrm{A}$ ) is variable.

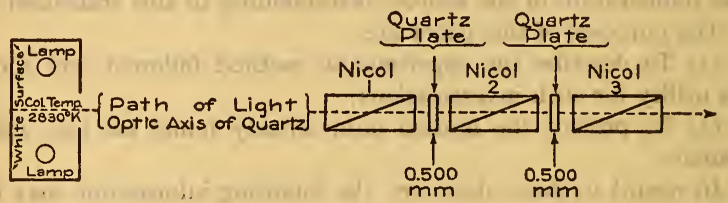

FIG. 4.-Essential parts of apparatus used to adjust the spectral distribution of the stimulus

Nicols $I$ and 2 are fixed. The spectral distribution of energy emerging from nicol 3 in the direction of the dotted arrow may be adjusted by rotation of nicol 3 relative to nicol 2 (angle, $\phi_{2}$ ).

In the use of the instrument for our present purpose, the Lummer-Brodhun cube $(\mathrm{L}, \mathrm{B})$ and the quartz plates $\mathrm{Q}_{\mathrm{r}}$ to $\mathrm{Q}_{\mathrm{rv}}$ (Fig. 5) are removed.

\section{METHOD OF ADJUSTING THE STIMULUS ${ }^{21}$}

(A) THEORY OF METHOD

The essence of the method of producing and adjusting the spectral distribution of the stimulus is this:

The spectral distribution of a source is modified by rotatory dispersion by allowing the energy to pass through the system of nicols and quartz plates shown in Fig. 4, which system is equivalent to a blue filter of adjustable spectral transmission, the adjustment being made by rotation of the nicol 3 , as will be further explained below.

Illumiıation is obtained from two 300 -watt, gas-filled tungsten lamps in a magnesia-lined box disposed as shown in Fig. 4. These lamps are operated at a constant current previously determined

\footnotetext{
19 Ann. d. Phys. (4), 39, pp. 545-568; 1912.

${ }^{20}$ Compare definition of $\phi_{1}$ in Section II, 2, A.

I C. Priest, Radiant energy at high temperatures, J. Op. Soc. Am.; March, r92x.
} 


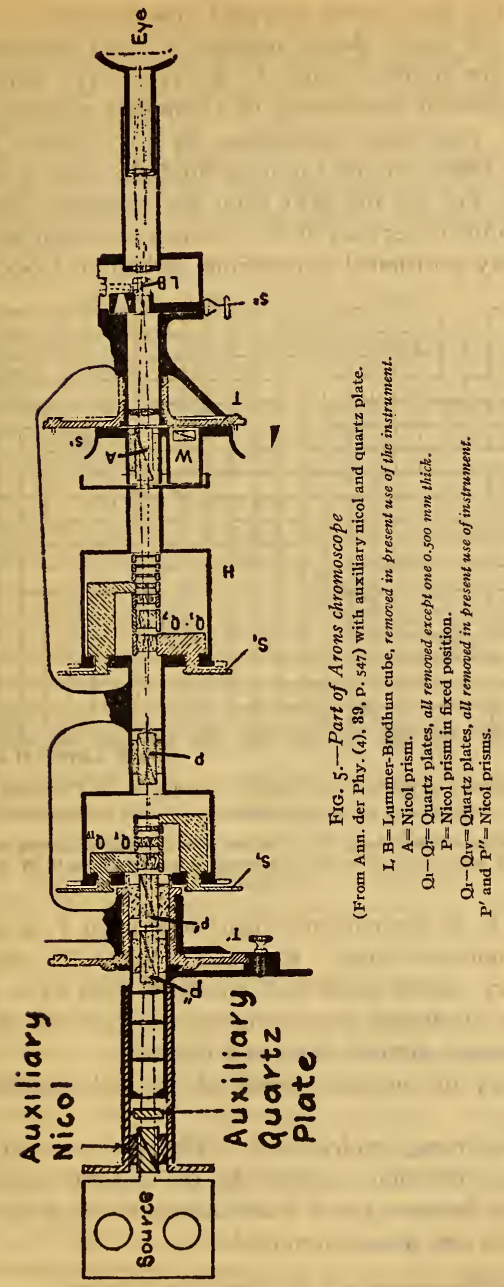


such that the light finally emerging from the ocular of the chromoscope with all quarts plates removed is color matched with the light from the standard lamp, B. S. I 7 I 7 at 118 volts, known to have the spectral distribution of a complete radiator at $2830^{\circ} \mathrm{K}$ (Fig. 6). ${ }^{22}$ This initial calibration by color match was accomplished by means of the Lummer-Brodhun cube in the chromoscope (L B, Fig. 5), the light from the standard lamp being reflected into the outer part of the Lummer-Brodhun field by means of a suitably positioned magnesium carbonate block.

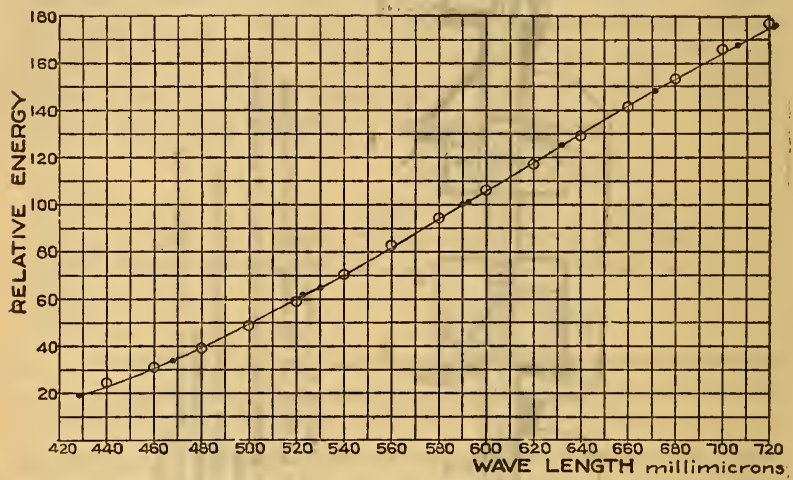

FIG. 6.-Comparison of spectral distributions of energy for the Planckian radiator (hypo. thetical) and the standard lamp used in this investigation

Solid curve: Planckian radiator at $2830^{\circ} \mathrm{K}$. (The solid black dots show the points actually computed.) Open circles: B. S. lamp I $_{7} 7$ at 118.0 volts as determined radiometrically by W. W. Coblentz, Bureau of Standards.

Nicol $\mathrm{P}^{\prime}$ is set permanently relative to nicol $\mathrm{P}$, so as to give a suitable brightness range. Rotation of nicol $\mathrm{P}^{\prime \prime}$, together with the auxiliary quartz plate and auxiliary nicol as a unit, serves to keep the brilliance approximately constant for all values of $\phi_{2}$ in the second method described below. ${ }^{23}$

The theory of the adjustment of spectral distribution is as follows:

$\phi_{1} \equiv$ angle through which nicol I (Fig. 4 ) is rotated relative to nicol 2 in a direction contrary to the natural rotation of the quartz plate between $I$ and 2 and measured from the extinction position with the quartz removed.

${ }^{22}$ From radiometric determinations by W. W. Coblentz, Bureau of Standards.

${ }^{23}$ Sec. II, $3, \mathbf{B}$. 
$\phi_{2} \equiv$ angle through which nicol 3 (Fig. 4) is rotated, relative to nicol 2 in the same direction as the natural rotation of the quartz plate between 2 and 3 , and measured from the extinction position with the quartz removed.

These three nicols and two quartz plates constitute, in effect, a selective light filter, the spectral transmission of which may be continuously adjusted by changing $\phi_{1}$ or $\phi_{2}$. The relative transmission is given by:

$$
\sin ^{2}\left(\phi_{1}-0.5 \alpha_{\lambda}\right) \sin ^{2}\left(\phi_{2}-0.5 \alpha_{\lambda}\right)
$$

where $\alpha_{\lambda} \equiv$ rotation of the plane of polarization by $1.000 \mathrm{~mm}$ of quartz for light of wave length $\lambda$.

If the current in the lamps (Figs. 4 and 5) is adjusted so that the energy transmitted by the nicols (Fig. 5) with the quartz removed has the visible spectral distribution of a complete radiator at $2830^{\circ} \mathrm{K}$, and the plates are then inserted and $\phi_{1}$ set at $170^{\circ}$, the resultant spectral energy distributions are determined by $\phi_{2}$. Distributions corresponding to certain values of $\phi_{2}$ are shown in Fig. 7, in which are also shown the spectral energy distributions of a hypothetical complete radiator at various temperatures as computed by the Planckian formula. It will be noticed at once that the spectral energy distributions obtained by this artifice conform closely to those given by the Planckian formula. That is, radiant energy having the spectral distribution (visible spectrum) of a complete radiator at any desired temperature between about 4000 and $7000^{\circ} \mathrm{K}$ can be obtained by giving $\phi_{2}$ a suitable value. In Fig. 8 such values of $\phi_{2}$ are plotted as a function of temperature. Given any value of $\phi_{2}$, we can obtain the corresponding temperature by reference to this graph.

\section{(B) EXPERIMENTAL VERIFICATION OF METHOD}

For the particular apparatus used the approximate validity of the relation shown in Fig. 8 has been checked experimentally by using the apparatus to determine color temperatures which could be checked fairly well by independent methods. More specifically stated, the checking procedure has been this: By means of the Lummer-Brodhun cube, L B (Fig. 5), light of known color temperature has been brought into juxtaposition in a photometric field with the light yielded by this apparatus (Figs. 4 and 5). $\phi_{2}$ has then been set to give a match of color quality, a brilliance match being simultaneously made by other adjustments. 


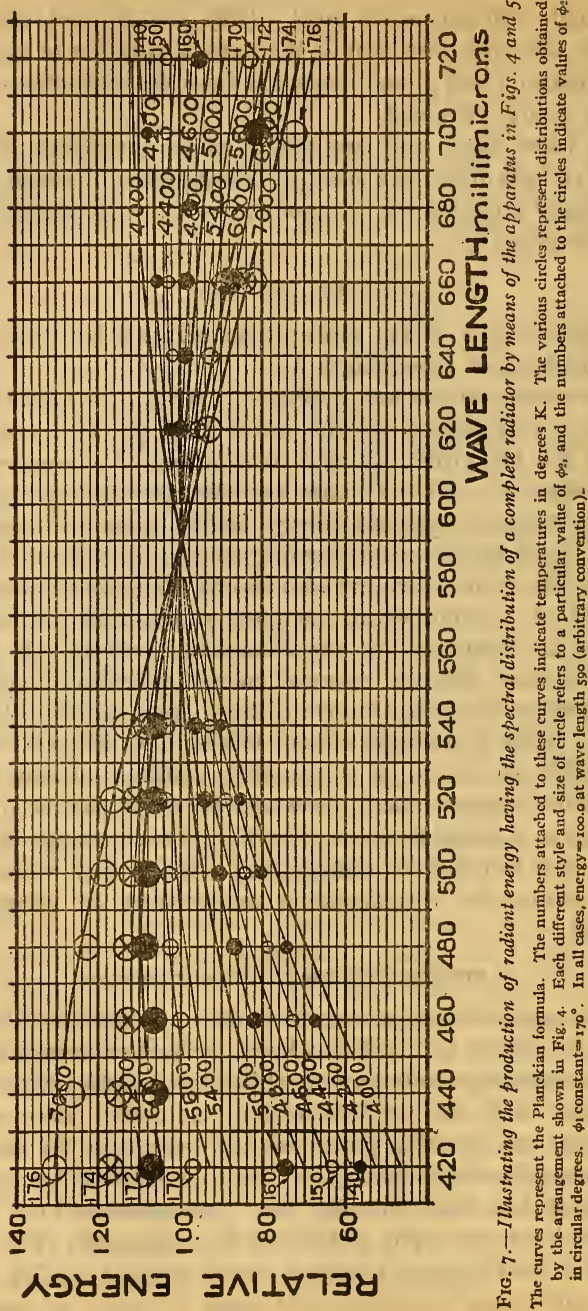


The color temperature corresponding to this value of $\phi_{2}$ has then been read from the graph in Fig. 8 and compared with the independently known color temperature. Three separate cases of such checking are to be considered, as follows:

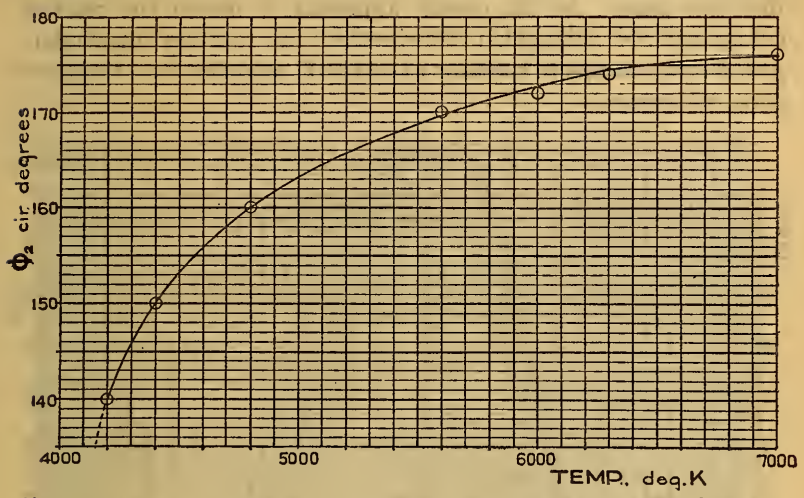

FIG. 8.-Temperature of energy distribution as a function of $\phi_{2}\left(\right.$ for $\left.\phi_{1}=I 70^{\circ}\right)$ with the arrangement shown in Fig. 4

Plotted from inspection of Fig. 7 .

(a) DifFuse Light FROM UNIFORM OVERCAST Sky.-

\begin{tabular}{|c|c|c|}
\hline Date & Hour & Color temperature, degrees Kelvin \\
\hline 1920 & & By apparatus in Figs. 4 and 5 \\
\hline $\begin{array}{l}\text { December } 1 \ldots . . \\
\text { December } 14 \ldots \\
\text { February........ }\end{array}$ & 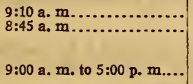 & 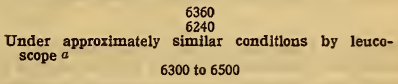 \\
\hline
\end{tabular}

a Priest, L,eucoscope, J. Op. Soc. Am., 4, p. 483: November, 1920.

(b) Light Having the Spectral Distribution of a ComPLETE RADIATOR AT $2830^{\circ} \mathrm{K}$ (B. S. LAMP I7I7, AT II 8.0 VOLTS) Modified by Transmission through "DAylite" Glass, B. S. I5 $648 \mathrm{~A}$.-The resultant spectral distribution of light ("luminosity curve") is shown by the dotted curve in Fig. 9. The solid curves in the same figure show the distributions of light for a Planckian radiator at several temperatures. It will be noticed that the distribution of light transmitted by the glass departs from the Planckian form in the following respects:

The curve is narrower; that is, relative to a complete radiator, the light has an excess of greenish yellow. 
There is a hump in the blue-green.

From the above it follows naturally that there is no value of $\phi_{2}$ for which the light from the apparatus (Fig. 5) will evoke a color perfectly matched with the color evoked by the light through the blue glass. At the closest approach to match the relative colors will be: Planckian distribution by rotatory dispersion, pale purple; complete radiator at $2830^{\circ} \mathrm{K}$ modified by "Daylite" glass, pale green.

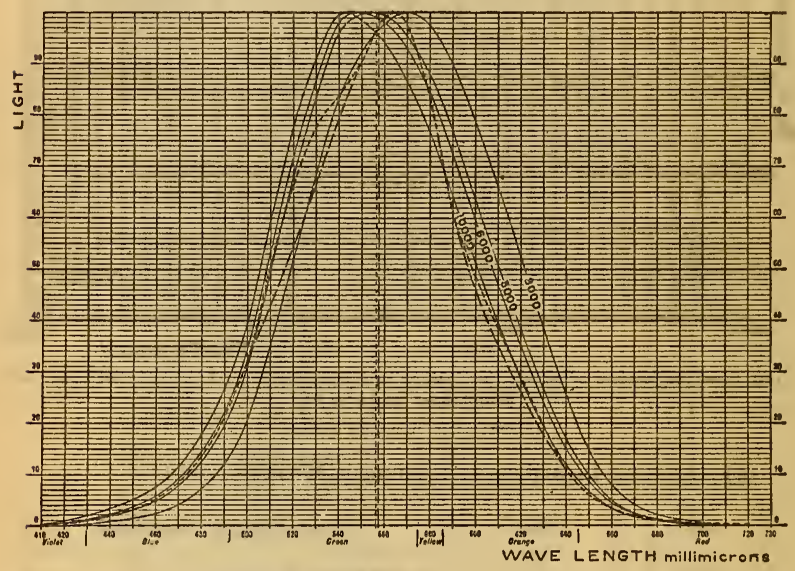

FIG. 9.-Comparison of spectral distributions of light in experimental test of temperature scale

Solid curves: Planckian radiator at temperatures indicated in degrees $\mathrm{K}$ by numbers attached to curves. Dotted curve: Planckian radiator at $2830^{\circ} \mathrm{K}$ modified by "Daylite" glass, B. S. $\times 5648 \mathrm{~A}$.

Dashed curve: Smoothed from dotted curve by removing humps.

This conclusion has been verified by direct observation in attempting to determine the color temperature by observation of the angle $\phi_{2}$.

However, we have determined the value of $\phi_{2}$ required to give the closest approach to color match; that is, the green-purple contrast mentioned just above. We then reason as follows:

We would obtain this same value of $\phi_{2}$ for a distribution represented by the dashed curve in Fig. 9, while the approximation to color match in this case would be closer.

We would obtain this same value of $\phi_{2}$ for a Planckian distribution having the same wave length of center of gravity as the dashed curve, and the color match would be perfect. 
In line with this argument the following data are presented:

Color temperature from observed $\phi_{2} \ldots \ldots \ldots \ldots \ldots \ldots \ldots \ldots \ldots \ldots \ldots \ldots 6_{500^{\circ} \mathrm{K}}$ $\lambda_{\mathrm{o}}$ Planckian radiator at this temperature (from Fig. 3 ) $\ldots \ldots \ldots \ldots \ldots \ldots .457 .4 \mathrm{~m} \mu$

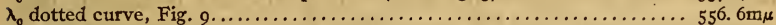

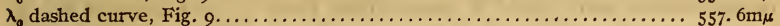

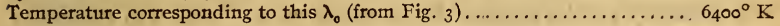

(c) Light Having the Spectral Distribution of a Complete RADIATOR AT $2360^{\circ} \mathrm{K}$ (NELA RESEARCH LABORATORY VACUUM TUNGSTEN STANDARD LAMP) MODIFIED BY TRansmission THROUGH "Daylite" Glass, B. S. I5 648 A.-The resultant spectral distribution of light is shown by the dotted curve in Fig. Io.

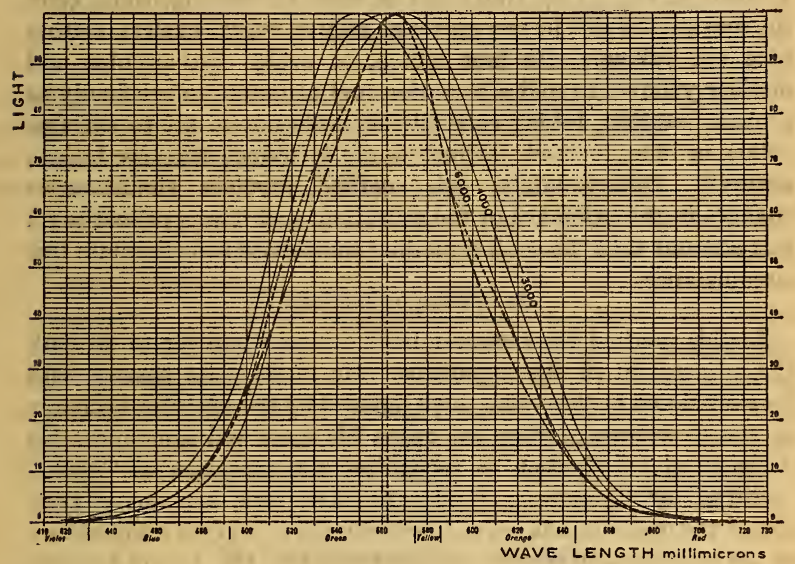

FiG. I0.-Comparison of spectral distributions of light in experimental test of temperature scale

Solid curves: Planckian radiator at temperatures indicated in degrees $\mathrm{K}$ by numbers attached to curves. Dotted curve: Planckian radiator at $2360^{\circ} \mathrm{K}$ modified by "Daylite" glass, B. S. $15648 \mathrm{~A}$.

Dashed curve: Smoothed from dotted curve by removing humps.

The same remarks and line of argument presented under $(b)$ just above apply here with the exception that in this case the greenpurple contrast is less; that is, a closer approximation to color match can be obtained by adjustment of $\phi_{2}$.

Similarly, the following data analogous to those given under (b) are presented in this case:

Color temperature from observed $\phi_{2} \ldots \ldots \ldots \ldots \ldots \ldots \ldots \ldots \ldots \ldots \ldots \ldots, 4650^{\circ} \mathrm{K}$ $\lambda_{0}$ Planckian radiator at this temperature (from Fig. 3 ) $\ldots \ldots \ldots \ldots \ldots \ldots, 562.25 \mathrm{~m} \mu$

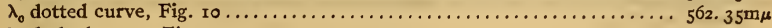

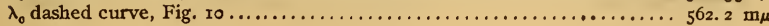
Temperature corresponding to this $\lambda_{0}$ (from Fig. 3 ) ............. $4675^{\circ} \mathrm{K}$ $51645^{\circ}-21-3$ 
While the data given under $(a),(b)$, and $(c)$ just above do not afford a rigorous check on the temperature scale, they do clearly indicate that no large errors exist. It seems safe to assume that temperatures near $5000^{\circ} \mathrm{K}$ determined from $\phi_{2}$ by means of Fig. 8 will certainly not be in error by as much as $100^{\circ}$ and will probably be correct to within $50^{\circ}$ or perhaps $25^{\circ}$.

\section{METHODS OF OBSERVATION}

(A) METHOD OF ADJUSTMENT BY TRIAL

In this method the observer adjusts the angle $\phi_{2}$ (nicol 3 , Fig. 4; nicol A, Fig. 5) by trial until he finds the setting which gives the sensation which he recognizes as gray or white (hueless, neither blue nor yellow). He first sets $\phi_{2}$ to evoke distinct blue and distinct yellow in rapid alternation and attempts to set finally at a mean position, taking care all the while not to set to extreme yellow or blue, for such settings would introduce selective fatigue effects. $^{24}$ Unfortunately, this method involves simultaneous changes in the brilliance of the sensation, and it was primarily on this account that the second method was devised to eliminate this circumstance.

\section{(B) METHOD OF ANSWERS}

In this method the observer has nothing whatever to do with the adjustment of the apparatus. He merely sits passive with his eyes closed at the ocular until signaled by the operator in charge of the experiment, when he opens his eyes and announces his decision as to whether he recognizes the sensation as "blue," "white," or "yellow." While the observer's eyes have been closed the operator has set $\phi_{2}$ to correspond to a given temperature of the hypothetical source (calibration curve, Fig. 8) and has also rotated the nicol $\mathrm{P}^{\prime \prime}$ (Fig. 5), together with the auxiliary plate and nicol, to a position previously determined to make the brilliance for this value of $\phi_{2}$ approximately the same as given by other values of $\phi_{2}$ with other corresponding rotations of $\mathrm{P}^{\prime \prime}$. That is, for each value of $\phi_{i}, \mathrm{P}^{\prime \prime}$ is rotated so as to produce approximately the same brilliance for observations at all temperatures. Having made these settings and noted that the current in the lamps has its correct standard value, the operator says: "Look" or "Ready, look." The observer opens his eyes and answers, "Blue," "White," or "Yellow," depending upon the sensation evoked, and immediately closes his eyes again. The operator

st Compare Sec. III, x. 
records the answer in a suitable form. The same procedure is then repeated.

As standard temperatures for tests by this method the following have been chosen after preliminary trials showed them to cover the proper range: ${ }^{25}$

For three observers-H. J. M., M. K. F., and I. G. P. $\left\{\begin{array}{c}6200^{\circ} \mathrm{K} \\ 5700 \\ 5300 \\ 5000 \\ 4700 \\ 4450 \\ 4200\end{array}\right\}$ For one observer-C. A. S.

At one sitting 20 trials are made at each temperature, interrupted by a rest period of about Io minutes, in the dark, when half through the complete set. The observer has no knowledge of the order in which the temperatures are set; ${ }^{26}$ the observers themselves say there are no circumstances to prejudice their decisions (except in the first sitting for I. G. P., Dec. I3).

The reaction time between the signal "Look" and the announcement of the decision varies from about $\mathrm{I}$ to 4 seconds, on the average, as determined with a stop watch operated by an assistant hearing both the signal and the answer. (This reaction time was measured only in some sittings but could not have been much different in the others.) The total time required for completing the observations in one sitting, including the rest period, is about 45 to 60 minutes. Besides a few preliminary trials not reported here each observer has made observations throughout 5 complete sittings, consisting each of 20 trials at each of 6 temperatures (except one observer, C. A. S., in first sitting; see record, Fig. 12).

\section{EXPERIMENTAL RESULTS}

\section{EFFECT OF PREVIOUS SELECTIVE FATIGUE}

Preliminary trials by the first method showed that the results were affected to a noticeable degree by the previous stimulus acting on the observer's eye. For example, the author when recording his own observations in a lighted room and, consequently, looking at the record sheet between observations, found his results

${ }^{25}$ In future work it will be desirable to choose, in addition to these, several more temperatures at smalle intervals on each side of the transition temperature.

${ }_{20}$ The order of setting the temperatures appears to influence the apparent precision with which the stimulus of gray is determined, but not the final value found. If the order of setting is from extreme to median temperatures the observer (I. G. P.) answers white for a greater range of temperature than if the reverse o1 der is followed. In the case of observers C. A.S., H. J. M., and M. K. F., the usual order has been from median to extreme temperatures. In the case of I. G. P. several orders have been followed. This question of the order of setting deserves further study: 
to vary with the illumination on the sheet, as shown in Table $\mathrm{I}$. The column headed "Temperature" gives the temperature for the Planckian stimulus evoking the gray sensation under the several conditions specified.

The effect of severely fatiguing the eye selectively with the long wave lengths (yellow, orange, and red) was found as follows: At the end of a long series of observations in the dark the observer (I. G. P.) looked through an orange glass at a bright sky for several minutes and then immediately began observations again. The following temperatures for the stimulus for gray were found:

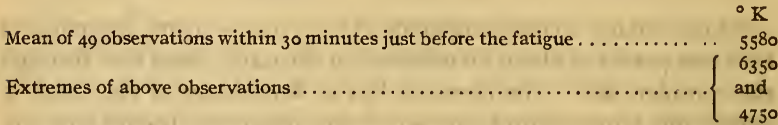

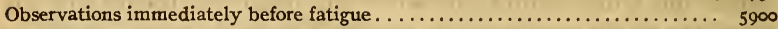

Observations immediately after fatigue................... less than . 4000

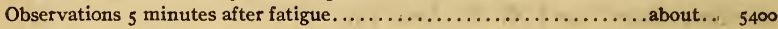

Observations 8 minutes after fatigue............................ 6000

Observations to minutes after fatigue...................... 5800

It will be noticed that while the immediate effect of this selective fatigue was pronounced the recovery was rapid and complete within 10 minutes. Considering the extreme nature of the fatiguing stimulus in this case and the rapidity of recovery from it, we have concluded that under ordinary circumstances a ro to 15 minute rest in the dark before beginning observations is sufficient to bring the eye to what may be considered a standard nonfatigued state. This preliminary period of rest has accordingly been observed in all of the experiments under the second method. ${ }^{27}$

\section{RESULTS BY THE METHOD OF ADJUSTMENT BY TRIAL.}

This method has been followed only by the author himself. The only other observer (H. J. M.) who attempted it did not obtain reasonable or consistent results and complained that the unavoidable changes of brilliance prejudiced and vitiated his readings to such an extent that it was deemed wise to abandon the attempt.

The author made 209 such settings distributed about equally over 4 days. The results are summarized graphically in Fig. II in the following way:

A count has been made of the number of individual observations falling within each of the following temperature intervals: 4675$4925,4925-5175,5175-5425,5425-5675,5675-5925,5925-6175$, $6175^{-6425}, 6425^{-6675^{\circ}} \mathrm{K}$. These numbers (frequency of choice) 
are plotted as ordinates against the wave length of the center of gravity of the spectral distribution of light ${ }^{28}$ for the mean temperature of the interval. Temperatures corresponding to $\lambda_{c}$ are given in the upper margin of the figure. Inspection of Fig. II shows that the mode (maximum ordinate) of this distribution of choices falls at about $5400^{\circ} \mathrm{K}$. The arithmetical mean of the 209 temperatures is $5480^{\circ} \mathrm{K}$.

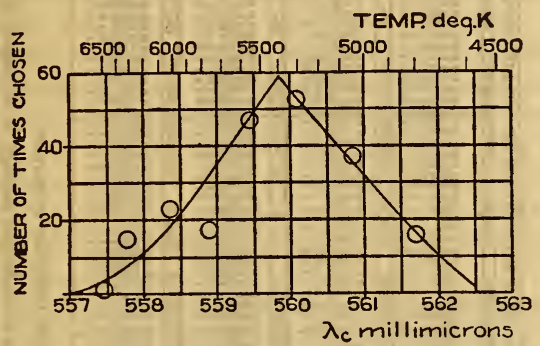

FIG. Ir.-Distribution of 200 choices of black body stimuli found to evoke the gray sensation by method of adjustment by trial

Obs. I. G. P. Dates: Dec. $1-4$, inc., $x 920$.

TABLE 1.-Showing Effect of Previous Stimulus on Determinations of the Stimulus of Gray

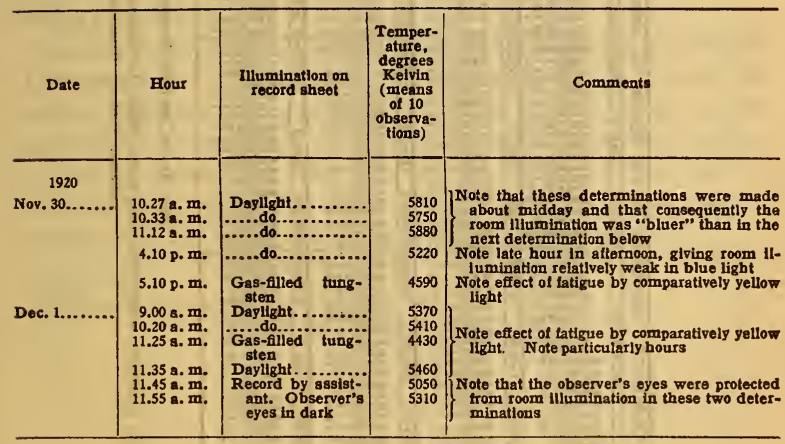

\section{RESULTS BY THE METHOD OF ANSWERS}

Aside from a few unsystematic preliminary trials, the complete transcript of the record of all determinations so far made by the

as Compare Figs. 1 and 3. 


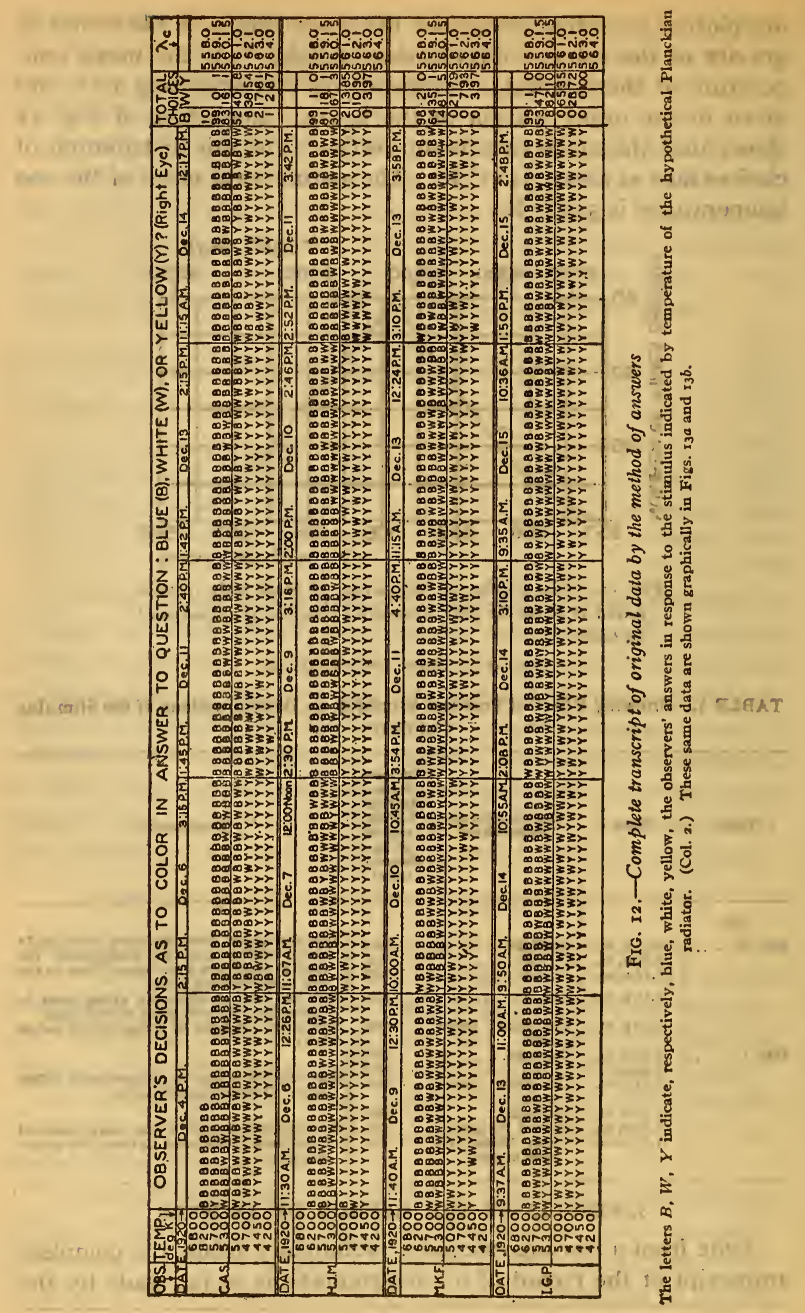


method of answers is shown in Fig. I2, which, in connection with the description of the method given above, should be self-explanatory

While simple inspection of the tabular presentation of the data in Fig. I 2 will serve to indicate roughly the temperature a Planckian radiator would have in order that the radiant energy would evoke the gray sensation, a graphic presentation is much more instructive and indicates the temperature much more definitely. Such a graphic presentation is shown in Figs. $1_{3} a$ and $1_{3} b$. The scale of equal parts on the abscissa (bottom of each figure) is in terms of $\lambda_{0}$, while corresponding temperatures of the source are shown on a scale at the top of each figure. ${ }^{29}$ The ordinates show the probability of the observer's recognizing the stimulus as "blue," "white," or "yellow," as the case may be. ${ }^{30}$. It is evident that the stimulus of gray is located (in terms of $\lambda_{\mathrm{c}}$ or temperature) by the intersection of the blue and yellow curves.

Within the experimental uncertainty, the $\lambda_{c}$ coordinate of this intersection appears to be the same as the $\lambda_{\mathbf{c}}$ coordinate of the maximum of the white curve, as would be theoretically expected, while it can be determined more definitely. The probability of recognizing this stimulus as blue is equal to the probability of recognizing it as yellow; while the probability of recognizing it as either is rather low, since the probability of recognizing it as gray is a maximum.

Values of temperature and of $\lambda_{\mathrm{o}}$ corresponding to the intersection of the blue and yellow curves are shown in Table 2 under the caption "Average stimulus for gray:" The stimuli, which, according to these curves (Figs. I $3 a$ and $I_{3} b$ ), will always be recognized as blue or yellow are also specified in Table 2. The spectral distributions of energy in the several limiting cases found in this investigation are shown in Fig. I 4, which is self-explanatory.

${ }^{20}$ Compare Fig. 3.

5o Explicitly, these ordinatcs show the value of the ratio:

Number of times the given color was named

Total number of decisions at the given temperature 

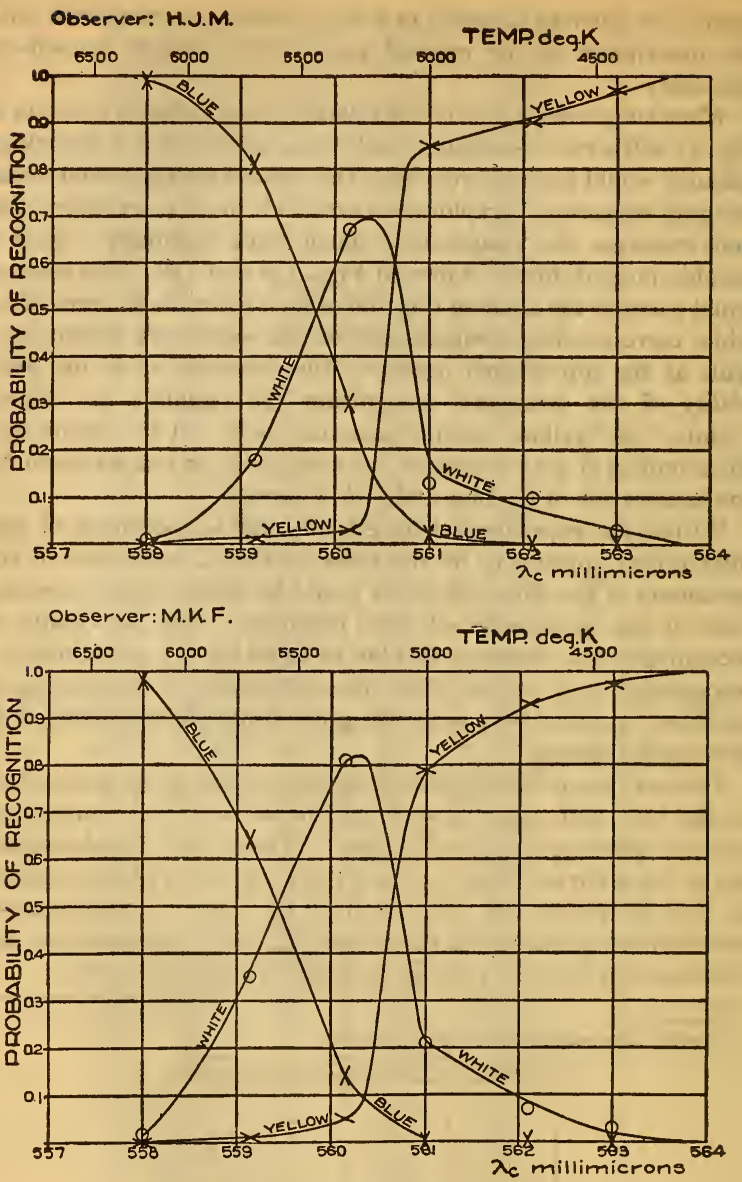

FIG. I3a.-Graphic presentation of data shown in Fig. 12 

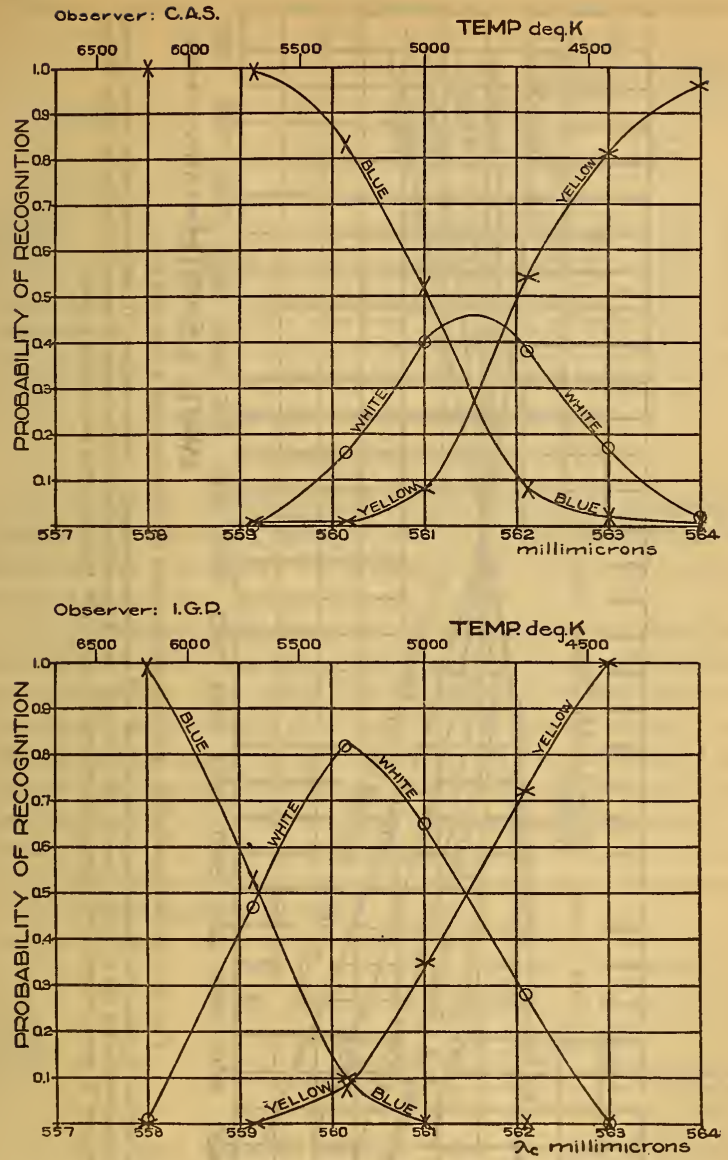

FIG. I3b.-Graphic presentation of data shown in Fig. 12 


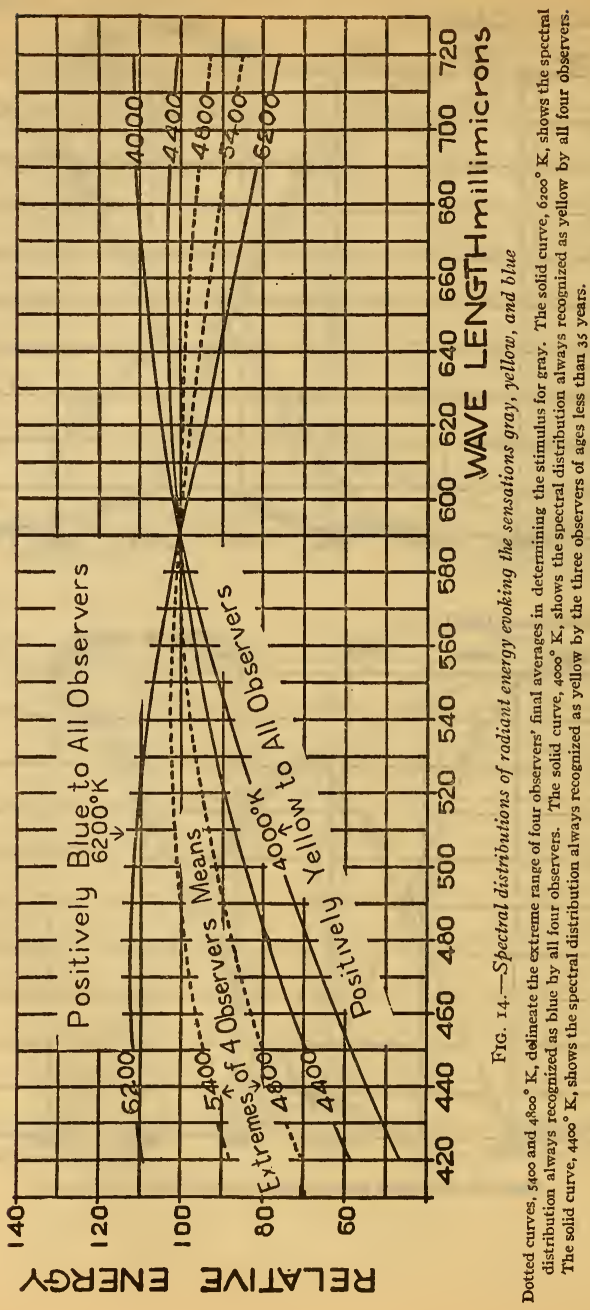


TABLE 2.-Results of Determination of Stimulus of Gray by Method of Answers

\begin{tabular}{|c|c|c|c|c|c|c|c|c|}
\hline \multirow{2}{*}{ Observer } & \multirow{2}{*}{ Age } & \multirow{2}{*}{ Sex } & \multicolumn{2}{|c|}{$\begin{array}{l}\text { Average stimu- } \\
\text { lus for gray }\end{array}$} & \multicolumn{2}{|c|}{$\begin{array}{c}\text { Stimulus } \\
\text { ALWAYS } \\
\text { evoking yellow }\end{array}$} & \multicolumn{2}{|c|}{$\begin{array}{l}\text { Stimulus } \\
\text { ALWAYS } \\
\text { evolring blue }\end{array}$} \\
\hline & & & $\begin{array}{l}\text { Tem- } \\
\text { pera- } \\
\text { ture }\end{array}$ & $\lambda_{0}$ & $\begin{array}{l}\text { Tem- } \\
\text { pera- } \\
\text { ture }\end{array}$ & $\lambda_{0}$ & $\begin{array}{l}\text { Tem- } \\
\text { pera- } \\
\text { ture }\end{array}$ & $\lambda_{0}$ \\
\hline 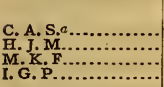 & $\begin{array}{l}50 \\
28 \\
34 \\
35\end{array}$ & 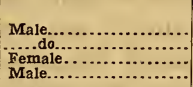 & $\begin{array}{l}{ }^{\circ} \mathrm{K} \\
4850 \\
5200 \\
5200 \\
5300\end{array}$ & $\begin{array}{r}\mathbf{m}_{\mu} \\
561.5 \\
560.4 \\
560.4 \\
560.2\end{array}$ & $\begin{array}{l}{ }^{\circ} \mathrm{K} \\
4000 \\
4200 \\
4200 \\
4450\end{array}$ & $\begin{array}{l}\mathbf{m} \mu \\
565 \\
564 \\
564 \\
563\end{array}$ & $\begin{array}{l}{ }^{\circ} \mathrm{K} \\
5750 \\
6200 \\
6200 \\
6200\end{array}$ & $\begin{array}{l}\mathbf{m \mu} \\
559 \\
558 \\
558 \\
558\end{array}$ \\
\hline Mean of all. ....... & -...... & n.................... & 5140 & 560.6 & 4200 & 564 & 6090 & 558.2 \\
\hline Mean of last three.. & $\ldots \ldots$ & $\cdots$ & 5230 & 560.33 & 4280 & 563.7 & 6200 & 558 \\
\hline
\end{tabular}

$a$ The cornea of thls observer's eye is injurea, and thls fact may invalidate his data to some extent.

\section{SUMMARY AND CONCLUSIONS}

\section{PRINCIPAL CONCLUSIONS}

On account of the limited amount of data obtained no generalization as to the average stimulus of gray can be drawn from this investigation. However, the principal conclusions may be summarized as follows:

(I) A practical method suitable for determining the Planckian stimulus of gray has been developed and thoroughly tested experimentally. The yellow-blue transition has been found to be a much more definite phenomenon than was anticipated, and definite, unambiguous results can be obtained in determining the hypothetical source temperature marking this transition. ${ }^{31}$ The method of observation settled upon (method of answers) is easy of application and entirely satisfactory.

(2) This yellow-blue transition temperature has been determined for four individuals, as follows:

\begin{tabular}{|c|c|c|c|}
\hline & Observer & Age & Temperature \\
\hline $\begin{array}{l}\text { C. A.S. } \\
\text { H.J.M } \\
\text { M. K.F } \\
\text { I. G.P. P. }\end{array}$ & (1, & $\begin{array}{l}50 \\
28 \\
34 \\
35\end{array}$ & $\begin{array}{ll} & { }^{\circ} \mathrm{K} \\
4850 & \\
5200 & \\
5200 & \\
5300 & \text { (second method) } \\
5400 & \text { (first method) }\end{array}$ \\
\hline
\end{tabular}

(3) The most probable average value for the yellow-blue transition temperature, based on these four individuals, is about $5200^{\circ} \mathrm{K}$. That is to say, based on these limited data, the best representative temperature for a Planckian radiator, in order that

u Compare Fig. $1_{3}$ and Table a. 
its radiant energy shall evoke the gray sensation in the average individual, is $5200^{\circ} \mathrm{K}$.

(4) There is an indication that the yellow-blue transition temperature depends upon the observer's age, but no conclusion on this point can be positively affirmed.

(5) With regard to change in the wave length of the center of gravity of the spectral distribution of light, the transition from yellow to blue is remarkably abrupt and well defined. ${ }^{32}$ The wave length of the center of gravity for gray is determined for each observer with an uncertainty less than I millimicron. A change of about 6 millimicrons in the wave length of center of gravity changes the sensation from undoubted yellow to undoubted blue; that is, this change covers completely the observer's range of doubt as to whether the sensation should be called blue or yellow and within which it may be called white. The range of the four observers' determinations of the wave length of the center of gravity for white is about $\mathrm{r} .3$ millimicrons. The range for three of the observers of nearly the same age is only 0.2 millimicron. ${ }^{33}$

(6) The effect of previous selective fatigue on the determination of the yellow-blue transition temperature is very noticeable but disappears in a few minutes. ${ }^{34}$

\section{INCIDENTAL CONCLUSIONS}

A number of standards for "average daylight," "average sunlight," and "white light" (objective) have been proposed more or less definitely heretofore. Some of these are compared with our present results in the following table:

\begin{tabular}{|c|c|c|c|}
\hline Authority & Designation of standard & Temperature & $\lambda_{c}$ \\
\hline This paper... & 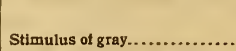 & $\begin{array}{l}{ }^{\circ} \mathrm{K} \\
5200\end{array}$ & $\begin{array}{l}m \mu \\
560.4\end{array}$ \\
\hline $\begin{array}{l}\text { Priest's representation of Ab- } \\
\text { bot's data (Phys. Rev., 11, p. } \\
\text { 502; 1918. Fig.1, open circles) }\end{array}$ & $\begin{array}{l}\text { Average noon sunlight at } \\
\text { Washington }\end{array}$ & $\underset{\text { (Not strictly Planckian dis- }}{5300}$ & 560.0 \\
\hline $\begin{array}{l}\text { H. E. Ives's (Trans. I. E. S., } \\
\text { pp. 198, 202; April, 1910) }\end{array}$ & "Average daylight." "White" & 5000 & 561.0 \\
\hline $\begin{array}{l}\text { H. P. Gage ("Daylite" glass, } \\
\text { Sibley Jour, of Eng., 30, No. } \\
\text { 8; May, 1916) }\end{array}$ & $\begin{array}{l}\text { "Average dayllght," "Sun } \\
\text { outside the earth's atmos- } \\
\text { phere" }\end{array}$ & $\begin{array}{c}\text { (Nat strictly Planckian dis- } \\
\text { tribution) }\end{array}$ & $\begin{array}{l}557.5 \\
\text { to } \\
556.7\end{array}$ \\
\hline
\end{tabular}

${ }^{32}$ Compare Fig. 13 and Table 2.

${ }^{33}$ It should be noted that the wave length of center of gravity $\left(\lambda_{0}\right)$ considered here is, in every case, that computed from our tentative standard of average visibility (dotted curve, Fig. 2 ) and is not referred to the observer's own individual visibility. In further work it will be desirable to compute also $\lambda$ 。

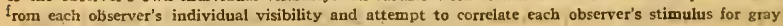
with his visibility.

\& Compare Sec. III, I. 
Accepting our stimulus of gray given above as a tentative standard, we may conclude that under our standard conditions ${ }^{35}$ various stimuli will evoke sensations as follows:

\section{Abbot-Priest}

Stimulus

Sensation

Average noon sun.$\ldots \ldots \ldots \ldots \ldots$ Very nearly gray

Winter sun or sun in morning or Pale greenish yellow. By simultaneous afternoon

Noon summer sun contrast standard gray appears pale purple. (Confirmed by experiment)

Ives's "Average daylight," $5000^{\circ} \mathrm{K} . .$. . Very pale yellow or perhaps gray

Gage's "Average daylight," $7000^{\circ} \mathrm{K}$...... Blue. (Confirmed by experiment with "Daylite" glass, B. S. 15648 A)

The spectral distributions of these stimuli and of some common artificial sources are shown in Fig. 15.

The average noon sunlight derived from Abbot's data is accordingly found to be a close approximation to the stimulus for gray. However, it is to be noted that this average sunlight does not conform strictly to a Planckian ("black-body") spectral distribution, and on this account, as well as on account of the small difference in $\lambda_{c}$, the color match may not be perfect.

The spectral distribution of sunlight at the earth's surface in the winter or in the morning or evening departs notably from a Planckian distribution in such a way that the colors by simultaneous contrast are:

Sun, pale greenish yellow.

Complete radiator, pale purple.

While, relative to the tentative gray found in this investigation, Ives's "average daylight" would be slightly yellow, it is quite possible that a more extensive statistical investigation would show it to be a good representative gray.

Gage's "average daylight" $\left(6500-7000^{\circ} \mathrm{K}\right)$ is definitely and unambiguously blue. This conclusion has been confirmed by direct experiment by the method of answers applied to this stimulus. $^{36}$ It was called blue ro times out of Io, the observer (H. J. M.) being under the impression that the trials were being made with the variable rotatory dispersion stimulus, and that the stimulus was being changed.

as Compare I, 2, above

${ }^{20}$ Source at $2830^{\circ} \mathrm{K}$ modified by "Daylite" glass (B. S. 15648 A.) 

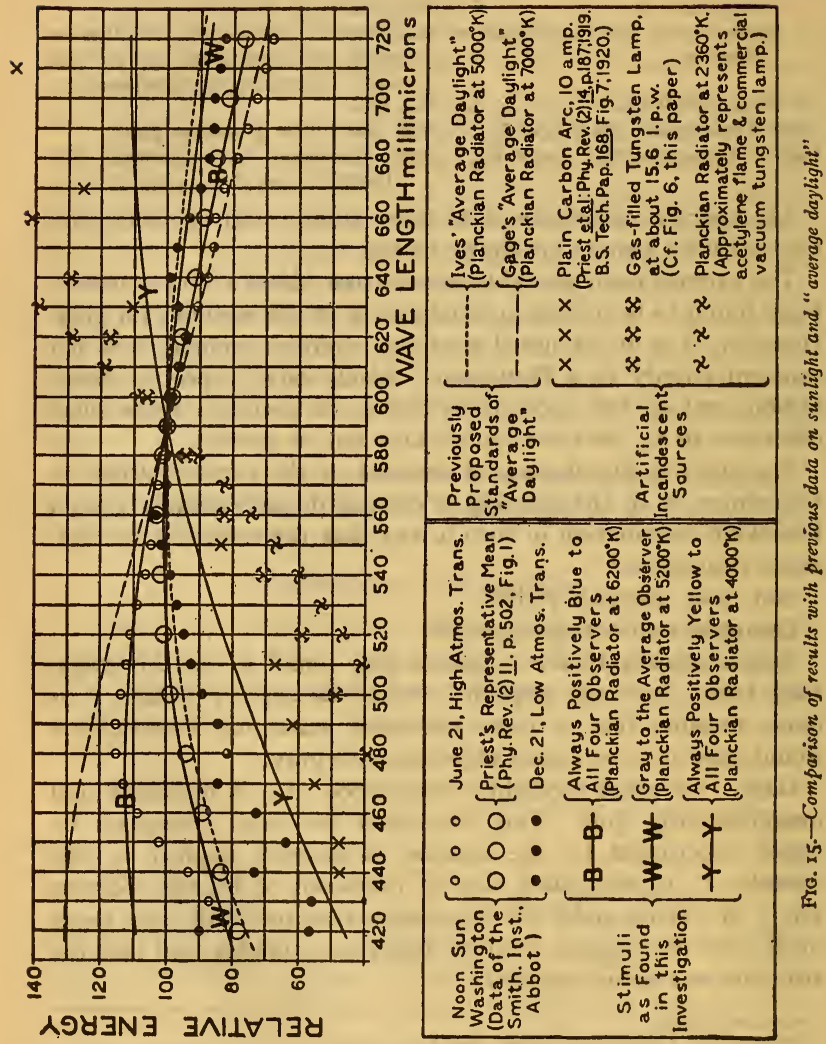


\section{SUGGESTIONS AS TO FUTURE WORK}

It would seem desirable that an extensive statistical determination of the Planckian stimulus of gray be made by means of the method of answers described in this paper.

The following suggestions relative to details in the method of answers should be considered in planning future work:

(I) Standard temperatures at which decisions are made should be taken at smaller intervals in the neighborhood of the transition temperature.

(2) It might be desirable to substitute the operation of a shutter controlled by the operator for the opening and closing of the observer's eyes.

(3) The effect of changing the following factors should be studied:

(a) The intensity of the stimulus;

(b) The size of the field;

(c) The order of taking the different temperatures;

(d) The exposure time, to be investigated by means of a timed shutter controlled by the operator, presenting the stimulus for a definite period, at the end of which the observer is to announce his decision;

(e) The effect of fatigue. In particular, it is proposed to compare the results obtained immediately after a night's sleep and before the eye has been subjected to any stimulus with those obtained at the end of a working day, and also with those obtained after prolonged exposure to various specified stimuli of moderate intensity.

Some extension of the present work will probably be undertaken at the Bureau of Standards during the coming year, and it is also to be hoped that other investigators will undertake such determinations independently.

WASHINGTON, February 10, 1921. 


\section{APPENDIX}

\section{THE DESIRABILITY OF AN EXTENSIVE STATISTICAL DETERMINATION AND CORRELATION OF THE CHARACTERISTICS OF VISION}

That part of visual optics dealing with the relations of stimulus and sensation (the visual psychophysical relations) long ago reached the stage where it would have been profitable to classify and set in order the problems awaiting solution to the end that they might be attacked in an orderly and effective manner. We are indebted to Nutting and to Richtmyer for several interesting and stimulating papers which point the way in this direction, but aside from these the author is not aware of any systematic attempt to survey this field. The outline below is the result of several years' thinking on this subject incident to the problems confronting one who has to deal daily with colorimetry and color specifications from a practical point of view. It represents a digest of purely scientific data urgently needed for practical (and often utilitarian) purposes. Careful consideration reveals the fact that these are the same data needed in order to advance "pure" science in the matter of elucidating the phenomena of color perception. The purpose of this appendix is to direct attention to this comparatively neglected field of research in the hope that it may act as a stimulus to more intensive cultivation. Occasion is also taken to point out, in this connection, the general utility of the "method of answers" used in the preceding paper.

This outline is to be regarded merely as the tentative result of an attempt to set in order, in a preliminary way, the subject matter dealt with. It will, of course, require revision and amplification and is of no permanent didactic value. It may serve as a temporary basis for discussion.

The cardinal features of the visual response to stimulation by radiant energy which are susceptible to quantitative study may be classified as follows (at least in part): r. To Be Determined as Functions of Frequency (or Wave Length) and Intensity of Stimulus and Size of Field Viewed.

(A) The visibility of radiant energy. [1] ${ }^{37}$

(B) Contrast sensibility-the least change in intensity of stimulus perceptible as a change in brilliance. [2]

(C) Hue sensibility - the least change in frequency (or wave length) perceptible as a change in hue. [3] (Hue sensibility mustalso be determined as a function of purity. [4] (Cf. Watson, Proc. Roy. Soc., London, B, 84, pp. I18-121; rgtr.)

(D) Saturation sensibility - the least change in purity perceptible as a change in saturation. [4]

(E) The three "primary sensations." [5]

(F) The time rates of adaptation-growth and decay of sensation with duration of stimulus- " persistence of vision." [6]

(G) The names for colors evoked by homogeneous stimuli. [7]

${ }^{17}$ A classified bibliography follows this Appendix. Reference to the bibliography is made in the Appen. dix by citing the bibliography group number in black-face type.

260 
2. To Be Determined as Functions of Intensity of Stimulus and the Size of the Field Viewed.

(A) The frequencies (or wave lengths) of the stimuli of complementary hues. [8]

(B) The relative intensities of the homogeneous stimuli of complementary hues required to be mixed to evoke the gray sensation. [9]

(C) The frequencies of the three homogeneous stimuli best suited to evoke the gray sensation by their joint action. [10]

(D) The relative intensities of the three homogeneous stimuli required to be mixed to evoke the gray sensation.

(E) The Planckian spectral distribution of energy required to evoke the gray sensation. [11]

3. To Be Determined as Functions of Frequency (or Wave Length) of Stimulus and Size of Field Viewed.

(A) The least stimulus of perceptible brilliance (so-called "achromatic threshold"').

(B) The least stimulus competent to evoke a color of characteristic hue (so-called "chromatic threshold"). [12]

II

An extensive thoroughgoing statistical determination of these characteristics is desirable for the following reasons: (I) In order to provide reliable and comparable data for the study of vision as a pure science. (2) In order to provide a reliable scientific basis for practical colorimetry and color specification. (3) In order to provide a reliable scientific basis for the practical diagnosis of color-blindness.

III

In order to fully serve the purpose noted under II (3) above, it will further be necessary that the above data from each observer be correlated with his reactions to certain tests previously recommended and more or less generally used in the routine diagnosis of color-blindness. In the author's opinion, the more important of these tests are: [13]

I. Holmgren Yarns; [14]

2. Stilling Charts; [15]

3. Nagel Charts; [16]

4. Anomaloskop Reading (Rayleigh Equation); [17]

5. Leucoscope Reading; [18]

6. Edridge-Green "Colour Perception Spectrometer." [19] (The following improvements to the Edridge-Green instrument might perhaps be made for the sake of simple standard conditions: (I) Substitution of a grating for the dispersion prism in order to have a normal spectrum. (2) Use of standard artificial average noon sunlight for illumination by means of the arrangement proposed by Priest, Phys. Rev., (2), 11, p. 502, Fig. I; 1918.

7. Practical Tests for the Recognition or Confusion of Signal Lights under Actual Working Conditions.

Certain "lantern"' tests [20] have been proposed to simulate approximately such conditions. I would, however, propose in place of these a test, the essential features of which may be outlined as follows:

A test range would be provided, at opposite ends of which would be an actual standard railway signal lantern and the subject being tested. The length of this range should be the distance at which the engineer must recognize the signal in order to properly control his train.

The subject being stationed and his attention directed to the lantern, the signals shown and the time of showing would be automatically recorded on a chronograph record. 
The subject would indicate his reaction by suitably prescribed motion of a lever (which might imitate the engineer's throttle lever), and the time of this reaction would be recorded on the same chronograph record.

Determinations should be made at several intensities, and a number of determinations should, of course, be made for each individual.

It will be observed that a notable merit of this proposed test lies in the fact that it records not only the subject's decision as to the signal, but also the time it took him to make the decision, which is a vital factor in this case.

\section{IV}

It is obvious that in order to yield the maximum information all of these characteristics should be determined for the same subjects.

It is also obvious that they should be correlated with reference to the following variables as to the subjects: (1) race, (2) sex, (3) age.

The magnitude of such an investigation, comprehending several hundred individual observers, is so discouraging that we are obliged to consider how it may be abridged with least loss. That is, of the whole outline above, what is most important to be done first?

The first question that arises is which of the above characteristics is it most important to determine on the same large group of individuals in order ( 1 ) to build up a consistent theory of color vision, (2) to elucidate the phenomena of "color-blindness" and its practical diagnosis, and (3) to provide the most needed data for practical colorimetry? These, in the author's opinion, are the ones listed under I, x, A to E and $I, 2, A$ to E, together with the practical tests for "color-blindness" under III.

In regard to the determination of the several characteristics as a function of the intensity of the stimulus, it appears that this should not be undertaken for the whole group, but rather in a very limited way as a subordinate auxiliary investigation. For the general investigation a standard intensity giving a comfortable brilliance high enough to avoid the Purkinje effect and low enough to avoid conspicuous or persistent afterimages should be chosen.

Likewise, the effect of field size should be studied in a similar limited subordinate investigation. The standard field size for the large group should be about 3 to $3.5^{\circ}$.

Similar remarks apply to other affecting conditions and circumstances, such as adaptation, previous fatigue, and simultaneous contrast, all of which may be studied in a limited way on small groups and suitable standard conditions chosen to apply to the large group.

In regard to determinations as a function of frequency (or wave length), such determinations should cover the whole group.

Visibility (I, I, A above), the "three sensations" (I, I, E above), and "hue sensibility" (I, I, C above) should be determined at from 20 to 30 points in the spectrum.

"Contrast sensibility" or "photometric sensibility" (I, r, B above) determinations might be limited to 3 (perhaps 5) homogeneous lights and "white" light (I, 2, Eabove).

The number of frequencies at which determinations of purity sensibility should be made will probably require a preliminary study.

Spectral colors should be named (I, r, G above) at probably 20 different frequencies.

In order to avoid, for the present, complications (which may be studied in detail later), all subjects should be in an approximately normal state of general health and not addicted to drugs.

\section{V}

Even with the limitations just imposed, the magnitude of the investigation is such that no practicable plan for carrying it out can be suggested at once. Our present purpose is merely to outline the work definitely and stress its importance. The needs of "pure" science and the needs of "applied" science, particularly in colorimetry 
and the diagnosis of "color-blindness," urgently require the results of such an investigation.

One point especially to be emphasized is the desirability of obtaining data on these several characteristics from the same individuals in order that-

(r) They may be correlated, merely as a matter of scientific interest.

(2) The results of the more or less empiric routine tests for color-blindness may be correlated with the more simple fundamental scientific data.

Of all these characteristics by far the most work of present value has heretofore been done on visibility, and comparatively reliable and satisfactory data on it are now extant. Nevertheless, there is at present some advocacy of a still more extensive statistical determination of this characteristic. In the author's opinion, it would be an exceedingly ill-advised and unfortunate expenditure of effort to undertake such an investigation without simultaneously determining the other characteristics, outlined above, for the same group of subjects. On the other hand, the getting together of a group of observers for such an investigation would afford the desired opportunity to carry out the other determinations, and the whole investigation would yield results of the utmost value.

\section{VI ${ }^{38}$}

In this section it is proposed to make a generalized suggestion relative to the experimental method of determining the psychophysical functions previously enumerated. The author is of the opinion that the "method of answers" described in the preceding paper, modified slightly to suit each particular case, would be advantageously applicable to most, and indeed probably all, of these determinations.

The advantages of this method over the more usual method of "adjustment by trial" are:

(I) Physiological.-A standard state of the visual apparatus may be more definitely prescribed and maintained, in that the effect of fatigue necessarily inherent in the method of adjustment by trial is eliminated.

(2) Psychological. - The decisions of the observer are bound to be less prejudiced by the incidental circumstances and conditions of the experiment.

(3) As to TrEatMent and INTERPRETATION OF THE EXPERIMENTAL Data.-The data obtained are conveniently amenable to treatment by statistical methods and can be graphically presented in a very cogent manner. (For example, Figs. $1_{3} a$ and ${ }_{13} b$ in the preceding paper.)

What is meant can best be made clear by an example, for which we take first the determination of the least stimulus competent to evoke the hueless sensation of brilliance. The observer's eye is brought to whatever state of adaptation may be desired and his attention fixed to a suitable fixation point, as is usual in such experiments. The operator controls the stimulus which is predetermined (but unknown to the observer) as to angular size, intensity, spectral composition, and time of duration. The observer answers "Yes" or "No," meaning thereby that the sensation is or is not evoked. The experiment proceeds in a manner quite similar to that described in the preceding paper. The probability of answering "Yes" and the probability of answering "No" are then plotted against the intensity of the stimulus (size, spectral composition, and duration being constant), or against any one of the variables, the others being constant. Equality of the probabilities of "Yes" and "No" evidently determines in a most rational manner the "just preceptible stimulus," while the slope of the curve indicates clearly the abruptness of the change from visible to nonvisible as the intensity of the stimulus changes.

As another example we may take the determination of least perceptible contrast (photometric sensibility). The operator sets the photometric field as to relative inten-

In connection with the preparation of this section the author wishes to acknowledge the value of sug. gestions made by Dr. P. V. Wells, who, after reading the preceding paper, advised emphasizing the more general applicability of the "method of answers." 
sity of stimuli in the two halves, the field being obscured by a shutter during this operation. He uncovers the field and asks the observer's decision. The observer answers: "right," "left," or "matched," meaning thereby, respectively, "the right half is brighter," "the left half is brighter," or "the field is matched." The "right," "left," and "matched" probability curves are then plotted against the ratio of intensities of stimuli in a manner quite analogous to the "blue," "yellow," and "white" curves in the preceding paper. Obviously, such curves will show contrast sensibility in a most definite and readily intelligible manner.

The same procedure will probably be found a valuable means of heterochromatic photometry, including the determination of the visibility of radiant energy.

Similar examples might be given for hue sensibility, saturation sensibility, etc., but it would involve a quite needless repetition of words; the reader can readily infer the slight modifications of method that would be made to suit each particular kind of determination.

It may or may not prove of interest later; but it is perhaps worth pointing out that by applying this same method we should be able to determine two other chromatic transition temperatures for the Planckian radiator, namely, red-yellow and blueviolet, analogous to the yellow-blue transition determined in the preceding paper.

\section{BIBLIOGRAPHY OF REFERENCES CITED IN APPENDIX}

The bibliographies given in the notes below are not complete, but are sufficiently comprehensive to give a good survey of the several subjects.

For general summarized information, see:

Nutting, The reactions of the retina to light, Am. J. of Physiol. Op., 1, pp. 142-170; r920. Report of Standards Committce on Visual Sensitometry, J. Op. Soc. of Am., 4, pp. 55-79; 1920.

\section{NoTES.}

1. Koenig (and Ritter), Wied. Ann., 45, pp. 604-607; 1892. Beiträge zur psychologie und physiologie der sinnesorgane (Helmholtz festschrift), pp. 309-388; Leipzig, 1891. Koenig's Ges. Abh. Physiol. Op., pp. 144-213; Leipzig, 1903.

Ives, Phil. Mag. (6), 24, pp. 853-863; 1912.

Nutting, Trans. I. E. S., 9, pp. $633-642 ;$ 1914.

Coblentz and Emerson, B. S. Sci. Papers, No. 303; 1917.

Reeves, Com. No. 55, Eastman Kodak Res. Lab., Trans. I. E. S., 13, pp. ror-rog; rgr8.

Hyde, Forsythe, and Cady, Astrophys. J., 48, pp. $65-88$; 1918.

Nutting, J. Op. Soc. Am., 4, pp. 55-60; 1920.

Watson, Proc. Roy. Soc. London, A, 88, pp. 404-428; igr3.

Watson, Proc. Roy. Soc. London, A, 89, pp. $3^{6-38}$; 1913.

Allen, Phil. Mag. (6), 21, pp. 604-607; 1911.

Allen, Phil. Mag. (6), 38, pp. 8r-89; 1919.

2. Koenig and Brodhun, Koenig's Ges. Abh. Physiol. Op., pp. 116-143; Leipzig, 1903.

Nutting, B. S. Bulletin, 5, p. 285 ; 1908-1909.

Blanchard, Phys. Rev. (2), 11, pp. 8r-99; r9r8.

Nutting, J. Op. Soc. Am., 4, p. 66; 1920.

3. Mandelstamm, Archiv für Opbth., 13, Abt. 2, pp. 399-406; 1867.

Dobrowolsky, Graefe's A rchiv, 18, Abt. 1, pp. 66-74; 1872.

Peirce, Am. J. of Sci., 126, pp. 299-302; 1883 .

Koenig and Diterici, Wied. Ann., 22, pp. 579-589; 1884.

Graefe's Archiv, 30, Abt. 2, pp. 171-184; 1884.

Koenig's Ges. Abb. Physiol. Op., pp. 23-33.

Uhthoff, Graefe's Archiv, 34, Abt. 4, pp. I-15; 1888 .

Exner, Wien. Sitzb., 111, 2A, pp. $875^{-877}$; 1902 .

Steindler, Wien. Sitzb., 115, 2A, pp. $39-62$; 1906.

Jones, J. Op. Soc. Am., 1, pp. 63-67; 1917 .

Nutting, J. Op. Soc. Am., 4, pp. 60-64; 1920.

Rayleigh, Proc. Roy. Soc. London, A, 84, pp. 464-468; r91a.

4. Purity $\equiv \frac{l_{\Lambda}}{l_{\Lambda}+l_{\nabla}}$,

where

$$
\begin{aligned}
& l_{\Lambda} \equiv \text { homogeneous light, } \\
& l_{\mathrm{W}} \equiv \text { '"white light," }
\end{aligned}
$$

as these stimuli are mixed in so-called monochromatic analysis.

Compare: Nutting, J. Op. Soc. Am., 4, p. 60; 1920.

Priest, J, Op. Soc. Am., 4, p. $400 ; 1920$.

Op. Soc. Am., Com. on Standards and Nomenclature, Subcom. on Colorimetry, Report igrg (preliminary draft), copy in Bureau of Standards Library, pp. $3^{8-40}$ and Table V. 
5. Nutting, Outlines of applied optics, p. 130, Fig. 38 ; Philadelphia, I912.

Exner, Wien. Sitzb., 111, 2A, pp. 857-875; 1902.

Koenig and Diterici, Zeit. für Psy. und Physiol. der Sinnesor., 4, pp. 24x-347; 1892.

Koenig's Ges. Abh. Physiol. Op., pp. 214-321; Leipzig, 1903.

Abney, Researches in color vision, Chapter XV; London, I9r3.

Allen, Phil. Mag. (6), 38, pp. 55-8r; 1919.

Allen, Am. Jour. Physiol. Op., 1, pp. 94-134; 2920.

6. Nutting, J. Op. Soc. Am., 4, pp. 70-76; r920.

Allen, Phys. Rev. (x), 11, pp. 257-280; 1900.

7. Helmholtz, Physiol. optics (third edition), 2, pp. 63-64.

Rood, Modern chromatics, p. 26; New York, 1879.

Crookes, Trans. Roy. Soc. London, A, 214, p. 4; I914.

Bezold, Farbenlehre, pp. 24-30; Braunschweig, 1874.

8. Helmholtz, v. Kries, v. Frey, Koenig, Angier, Trendelenhurg, and Diterici as quoted in Helmholtz; Physiol. optics (third edition), 2, p. 107.

Grünherg, Sitzb. Ak. Wien, 2A, 113, pp. 627-636; 1904.

9. Parsons, An introduction to the study of color vision, pp. 35-36; Cambridge University Press, 19r5.

10. Rood, Modern chromatics, pp. 120-122; New York, 1879 .

Watson, Text book of physics (fourth edition), p. 562; London, 1905.

Helmholtz, Physiol. optics (third edition), 2, pp. 138-140; 1911.

II. Troland, Trans. I. E. S., 13, p. 26; 1918.

12. Parsons, Introduction to the study of color vision, pp. 19, 60, 72, and 80; Cambridge University Press, 1915.

Abney, Proc. Roy. Soc. London, A, 83, pp. 290-297; 1910.

Abrey and Watson, Trans. Roy. Soc. London, A, 216, pp. 91-128; 1916.

Ives, Astrophys. J., 44, pp. 124-127; 1916.

Russell, Astrophys. J., 45, pp. 60-64; 1917 .

Reeves, Com. No. 5I, Eastman Kodak Research Laboratory.

Reeves, J. de Phys. (5), 7, pp. 68-74; 1917.

Blanchard, Phys. Rev. (2), 11, pp. 81-99; 1918.

Reeves, Astrophys. J., 47, pp. 141-145; 1918 .

13. Compare Black, Trans. I. E. S., 9, pp. 436-437; r914.

Jennings, Am. J. Physiol. Op., 1, pp. 77-93; 1920.

14. Holmgren, Color-blindness and its relations to railroads and the marine. (Original in Swedish) Upsala, 1877 .

Abridged translation, Smithsonian Inst. Report; 1877 .

Sep. Pub. by Smithsonian Inst.; 1878 .

Jeffries, Color-blindness; Boston, 1879 .

Rep. Com. on Color Vision (Rayleigh, chairman), Proc. Roy. Soc. London, 51, p. 298, and pp. 375-39r, 1892 .

15. Stilling, Pseudo-isochromatische tafeln zur prüfung des farbensinnes (fourteenth edition); Leipzig, 1913.

Koeliner, Die stoerungen des farbensinnes, p. 79; Berlin, 1912.

16. Nagel, Tafeln zur untersuchung des farbenunterscheidungs-vermögens, published by J. F. Bergmann; Wieshaden, rgrr.

Koellner, Die stoerungen des farbensinnes, pp. $67-69$.

17. Nagel, Zwei Apparate, etc., Zeit. für Augenh., 17, p. 20x; 1907.

Koellner, Die stoerungen des farbensinnes, pp. 69-77.

Rep. Com. on Standards and Methods of Examining the Color Vision (Williams, Black, and Jennings); Section on Ophthal., Am. Med. Assoc.; Chicago, 1914.

18. Koenig, Centralhlatt für prak. Augenh., 8, pp. 375-377; 1884 .

Brodhun, Ann. der Phys. und Chem., 34, pp. 897-918; 1888.

Priest, J. Op. Soc. Am., 4, pp. 448-495; 1920.

(See last citation for complete bibliography.)

19. Edridge-Green, Proc. Roy. Soc. London, B, 82, pp. 458-467; 1910.

Edridge-Green, Colour-blindness (second edition), p. rII; London, rgog.

Rayleigh, Proc. Roy. Soc. London, A, 84, pp. 464-468; 19 ro.

20. For example, Edridge-Green, Williams, Thomson.

Compare Rep. Com. on Standards and Methods of Examining the Color Vision (Williams, Black, and Jennings), Section on Ophthal., Am. Med. Assoc.; Chicago, 1914.

Thomson, A lantern for detection of color-blindness, Ry. Surg. J.; November, r907.

Edridge-Green, Colour-blindness (second edition); London, rgog.

Collins, Color-blindness, Pub. Health Bull. No. 92, U. S. Pub. Health Service; 1918. 


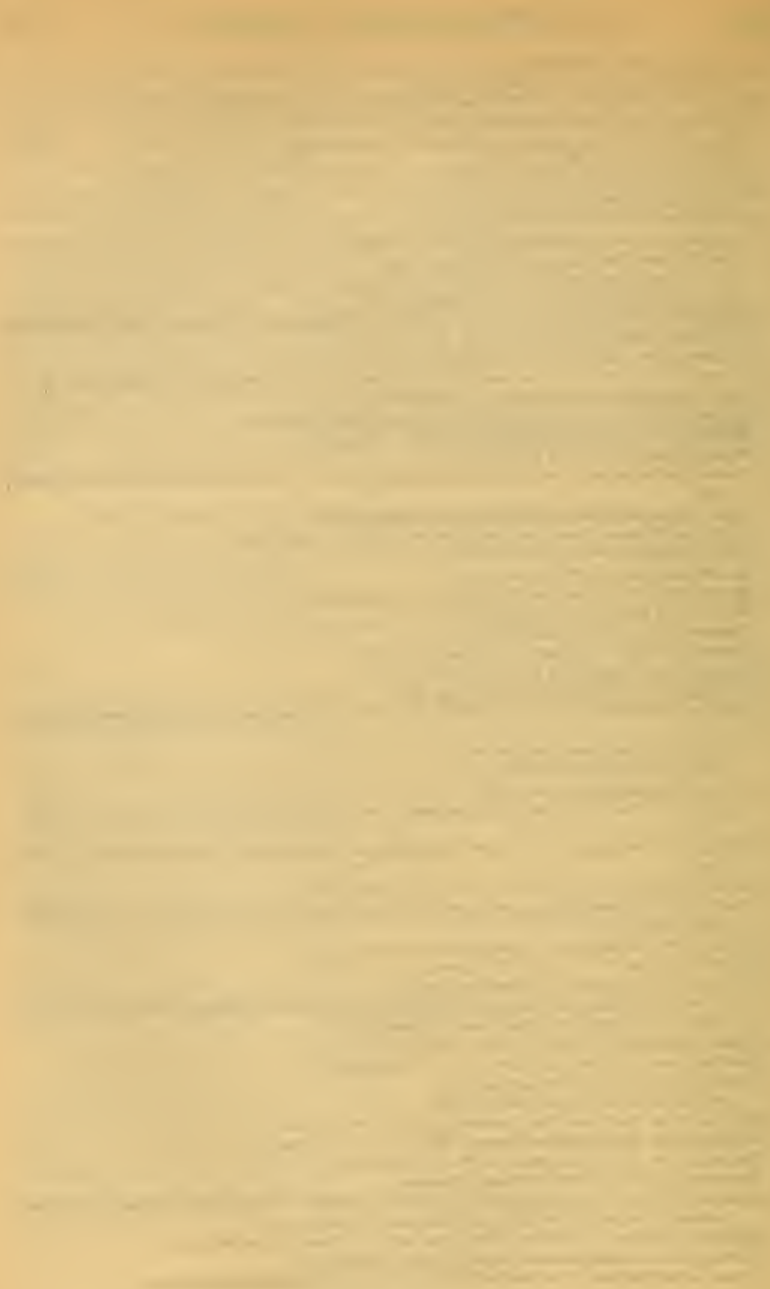










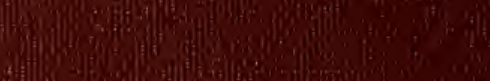

6h

flog ing

(1)

Whe

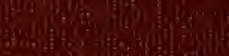

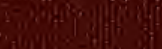

